\title{
Erratum to: Caprine pleuropneumonia in Beetal goats
}

\author{
Riaz Hussain • Muhammad Auon • Ahrar Khan • \\ Muhammad Zargham Khan • Fazal Mahmood • \\ Sajjad Ur-Rehman
}

Published online: 10 January 2012

(C) Springer Science+Business Media B.V. 2011

\section{Erratum to: Trop Anim Health Prod \\ DOI 10.1007/s11250-011-9922-1}

There are errors in the title and throughout text of this paper which wrongly states that $M$. mycoides subsp. capri causes contagious caprine pleuropneumonia (CCPP). This erratum should help prevent chaos in reporting the true causative organism of CCPP, Mycoplasma capricolum subsp. capripneumoniae. CCPP is an OIE listed and reportable disease.

This paper is about Mycoplasma mycoides subsp. capri infection, a cause of caprine pleuropneumonia (not CCPP). Thus in the title and in the text please read caprine pleuropneumonia for CCPP and the title should more correctly read:

'Caprine pleuropneumonia in Beetal goats'.

The online version of the original article can be found at http://dx.doi. org/10.1007/s11250-011-9922-1.

R. Hussain $(\varangle) \cdot$ M. Auon · A. Khan $\cdot$ M. Z. Khan · F. Mahmood Department of Pathology, Faculty of Veterinary Science,

University of Agriculture,

Faisalabad 38040, Pakistan

e-mail: driazhussain@yahoo.com

\section{S. Ur-Rehman}

Institute of Microbiology, Faculty of Veterinary Science,

University of Agriculture,

Faisalabad 38040, Pakistan 